\title{
BMJ Open Characterisation of asymptomatic patients and efficacy of preventive measures for SARS-CoV-2 infection in a large population of Southern Italy: a cohort study
}

\author{
Mario Masarone (D) , ${ }^{1}$ Emilia Vaccaro, ${ }^{2}$ Roberta Sciorio, ${ }^{1}$ Pietro Torre, ${ }^{1}$ \\ Antonio Della Vecchia, ${ }^{3}$ Andrea Aglitti, ${ }^{1}$ Rita Caliulo, ${ }^{2}$ Anna Borrelli, ${ }^{3}$ \\ Marcello Persico (iD ${ }^{1}$
}

To cite: Masarone M, Vaccaro E, Sciorio $\mathrm{R}$, et al. Characterisation of asymptomatic patients and efficacy of preventive measures for SARS-CoV-2 infection in a large population of Southern Italy: a cohort study. BMJ Open 2021;11:e043112. doi:10.1136/ bmjopen-2020-043112

- Prepublication history for this paper is available online. To view these files, please visit the journal online (http://dx.doi. org/10.1136/bmjopen-2020043112).

Received 24 July 2020

Revised 26 March 2021

Accepted 17 April 2021

Check for updates

(C) Author(s) (or their employer(s)) 2021. Re-use permitted under CC BY-NC. No commercial re-use. See rights and permissions. Published by BMJ.

${ }^{1}$ Internal Medicine and Hepatology Unit, Azienda Ospedaliera Universitaria 'San Giovanni di Dio e Ruggi d'Aragona', Salerno, Italy ${ }^{2}$ Molecular Biology Unit, Azienda Ospedaliera Universitaria 'San Giovanni di Dio e Ruggi d'Aragona', Salerno, Italy ${ }^{3}$ Hospital Health Direction, Azienda Ospedaliera Universitaria 'San Giovanni di Dio e Ruggi d'Aragona', Salerno, Italy

Correspondence to Dr Marcello Persico; mpersico@unisa.it

\section{ABSTRACT}

Background The SARS-CoV-2 pandemic has infected millions of people and has caused more than 2.30 million deaths worldwide to date. Several doubts arise about the role of asymptomatic carriers in virus transmission. During the first epidemic outbreak in Italy a large screening with nasopharyngeal swab (NS) was performed in those who were considered 'suspect' for infection.

Aims To report the results of the SARS-CoV-2 screening in a province in Southern Italy and to provide data on the COVID-19 epidemic and the burden of asymptomatic subjects.

Patients and methods A retrospective cohort study was set up in all healthcare facilities of the province (12 hospitals and 13 sanitary districts: primary, secondary and tertiary centres) with the aim to analyse the results of NS performed on all subjects suspected to be infected with SARS-CoV-2, either because they presented symptoms suggestive of SARS-CoV-2 infection, they were 'contacts' of positive subjects, they came from areas with high prevalence or they were healthcare workers. NS were performed and managed as indicated by international guidelines. The specimens were processed for SARS-CoV-2 detection by real-time PCR. Results A total of 20325 NS were performed from 13 March to 9 May 2020. Of these, 638 (3.14\%) were positive. 470 were asymptomatic, or $75.3 \%$ of persons who were positive. They were mostly among 'contacts' of symptomatic cases (428 of $470,91 \%$ ) and were in domiciliary isolation. Expression of three SARSCoV-2 genes did not differ between asymptomatic and symptomatic subjects. The strict measures with regard to social distancing led to a continuous decrease in cases during phase 1 .

Conclusions In a large area in Southern Italy, 3.14\% (638 of 20325 ) of the total subjects tested were positive for SARS-CoV-2. Most of them were asymptomatic (470 of $624,75.3 \%$ ), and of these $91 \%$ (428 of 470 ) were 'close contacts' of symptomatic subjects. The combination of social distancing together with the systematic screening of close contacts of COVID-19-positive symptomatic subjects seems to be an efficacious approach to limit the spread of the epidemic.

\section{Strengths and limitations of this study}

- The study reports on a retrospective cohort of SARSCoV-2-screened patients during the 'first wave' of the pandemic in Southern Italy.

- Screening was performed with nasopharyngeal swabs for SARS-CoV-2 real-time PCR detection from 9 March to 3 May 2020.

- It was performed on symptomatic subjects, asymptomatic contacts of positive subjects, subjects coming from areas with high prevalence and healthcare workers.

- The study reports on the prevalence, demographics and clinical characteristics of SARS-CoV-2-infected patients during that period.

- The main limitations are the study's retrospective nature and that the data presented are of a study cohort and not the whole population.

\section{INTRODUCTION}

COVID-19 is the clinical manifestation of an airborne infection caused by a Coronavirus species virus, which has been named 'severe acute respiratory syndrome coronavirus-2' (SARS-CoV-2), and was declared a pandemic by the WHO on 11 March $2020 .{ }^{1}$ In Italy, the epidemic outbreak led to adoption of a strict lockdown, banning all non-essential activities as early as 9 March 2020. 'Phase 1' of lockdown, which took place from 9 March to 3 May 2020, was intended to reduce the spread of infection, which to date (February 2021) has caused 2.650 million cases with 92.001 deaths in Italy. From 3 May 2020 movement restrictions among Italian citizens were minimised, thanks to reduction in the spread of infection, especially in the southern region, which led to 'phase 2' of lockdown, although 'social distancing measures' were maintained. ${ }^{2}$ 
SARS-CoV-2 has infected millions of people and has caused more than 2.34 million deaths worldwide at the time of writing. Its epidemiology has been largely investigated, with increasing evidence demonstrating its clinical manifestations can vary from an asymptomatic upper respiratory tract infection to a severe acute respiratory syndrome, leading to a necessity for intensive care, with a high risk of death from respiratory failure. ${ }^{3}$ Many speculations have been made on the epidemiology of the pandemic and in particular on the number of asymptomatic cases and their role in the spread of infection across the globe. ${ }^{4-6}$ Nevertheless, there are limited data on the burden of asymptomatic carriers, their number and their capacity to spread the infection. For these reasons, we here report the results of the SARS-CoV-2 screening activities conducted in a large single province in a region in Southern Italy (Campania) during the phase 1 and phase 2 lockdown in the country, with the aim to provide information on the coronavirus epidemic and the burden of asymptomatic infections.

\section{PATIENTS AND METHODS}

The present cohort study reports on the SARS-CoV-2 infection screening programme set up in the province of Salerno in Southern Italy during the so-called 'phase 1' of the lockdown period, which was decided by the Italian government from 9 March to 3 May 2020 in Italy, due to the spread of the COVID-19 epidemic in the country. The province of Salerno is located in the region of Campania in Southern Italy and happens to be the largest Italian province by extension $\left(4952 \mathrm{~km}^{2}\right)$ and number of municipalities (158), with a total population of about 1 million inhabitants. As soon as the lockdown was instituted in Italy, the regional government decided for a profound reorganisation of the healthcare system to face the emergency. ${ }^{7}$ Among all, a diagnostic service for SARS-CoV-2 by means of nasopharyngeal swab (NS) analysis was set up at the main university hospital, the San Giovanni di Dio e Ruggi d'Aragona Hospital. All national healthcare system facilities belonging to the local health company of Salerno (including 12 hospitals, 13 healthcare districts and several territorial service facilities, spanning all over the Salerno territory) performed NS on a daily basis, sending overnight stabilised specimens (in universal transport media, UTM) that were collected on-site to be centrally evaluated. ${ }^{8}$

During this phase, a universal screening was not provided to the entire population, and NS for COVID-19 were only performed, as mandated by the central and regional government, for the following reasons: symptoms suggestive of an upper respiratory tract syndrome and/or cough and/or fever without any other cause and/or contact (family members, cohabitants and/or coworkers and/or caregivers) with an infected subject and/or a person coming from geographical areas with high prevalence of infection (ie, Northern Italy regions). Moreover, NS were performed on all inpatients admitted to hospitals (with and without an upper respiratory tract syndrome) and all healthcare workers of the province.

NS were performed by healthcare professionals (doctors or nurses) who were preliminarily trained to perform specimen collection using the best procedures, as indicated by WHO. ${ }^{9} 10$

All subjects undergoing NS were asked to sign an informed consent and to respond to a brief questionnaire on age, sex, address, provenience and the symptoms they eventually had (no symptoms; mild symptoms: influenzalike or mild fever or cough or sneezing; symptoms: clinical presentation compatible with one of the five clinical presentations of COVID-19). ${ }^{11}$ In case of a patient who was in the hospital or in an emergency room, the operator who carried out the NS compiled the form with all the necessary data (including symptoms).

\section{NS analysis for SARS-CoV-2 detection}

NS were collected from all subjects and the sampled specimens were transferred to UTM (Copan, Mylan, Italy) and managed as indicated by the Centers for Diseases Control and Prevention guidelines. ${ }^{12}$ The Allplex 2019-nCoV Assay (Seegene, Seoul, South Korea), which has been demonstrated to be accurate for confirmation diagnosis of SARS-CoV-2 infection, was used on a Nimbus IVD and CFX96 Real-Time PCR automatic extractor (Seegene) to amplify three viral targets: the $\mathrm{E}$ gene (specific to the subgenus sarbecovirus), the $\mathrm{N}$ gene and the RdRP gene (both specific to SARS-CoV-2). ${ }^{13}$ Samples displaying at least two viral targets on real-time (RT)-PCR were considered positive, as previously indicated. ${ }^{13}$

\section{Patient and public involvement}

Due to its retrospective nature, this cohort study did not involve patients and the public in the design, or conduct, or reporting or dissemination plans.

\section{Statistical analysis}

All data collected were analysed using IBM SPSS Statistics for Macintosh V.26. Continuous variables were analysed with parametric or non-parametric tests, where appropriate. In particular, Student's t-test and Mann-Whitney test were performed for continuous variables, and $\mathrm{X}^{2}$ test with Yates correction or Fisher's exact test was used to compare frequencies and categorical variables. Before applying the correct analysis, a Kolmogorov-Smirnov 'goodness of fit' test for normality was performed to assess if continuous variables had normal or non-normal distribution. Statistical significance was defined when ' $\mathrm{p}<0.05$ ' in a two-tailed test with $95 \%$ CI.

\section{RESULTS}

From 13 March to 15 May 2020, a total of 20789 NS were performed and analysed. A total of 1097 swabs were positive for SARS-CoV-2 RNA. Out of 20 325, 638 (3.14\%) were newly diagnosed cases of COVID-19 and 464 were secondary samples collected during follow-up of the first 
Table 1 Characteristics of patients who underwent SARS-CoV-2 screening with nasopharyngeal swabs during 'lockdown phase 1'

\begin{tabular}{|c|c|c|c|c|}
\hline & Overall & SARS-CoV-2-positive & SARS-CoV-2-negative & $P$ value \\
\hline n (\%) & 13448 & $624(4.64)$ & $12824(95.36)$ & - \\
\hline Age, mean $( \pm S D)$ & $50.75( \pm 17.0)$ & $51.93( \pm 20.3)$ & $50.44( \pm 17.1)$ & 0.016 \\
\hline Sex (male/female), \% & $55.89 / 44.11$ & $55.8 / 44.2$ & $55.9 / 44.1$ & 0.946 (OR 0.994; 0.846-1.169) \\
\hline \multicolumn{5}{|l|}{ Symptoms, n (\%) } \\
\hline Asymptomatic & $12591(93.6)$ & $470(75.3)$ & 11651 (90.9) & 0.0001 \\
\hline Symptomatic & $1068(7.9)$ & $150(24.0)$ & $918(7.2)$ & \\
\hline Mild symptoms & $259(1.9)$ & $4(0.6)$ & $255(1.9)$ & \\
\hline \multicolumn{5}{|l|}{ Placing, n (\%) } \\
\hline Contacts & $10500(78.1)$ & $556(89.1)$ & $9944(77.5)$ & 0.028 \\
\hline Inpatients & $1151(8.5)$ & $25(4.0)$ & $1126(8.8)$ & \\
\hline ED patients & $505(3.7)$ & $36(5.8)$ & $469(3.7)$ & \\
\hline ICU patients & $48(0.3)$ & $2(0.3)$ & $46(0.3)$ & \\
\hline $\begin{array}{l}\text { Occupational health } \\
\text { surveillance }\end{array}$ & $1244(9.2)$ & $5(0.8)$ & $1239(9.7)$ & \\
\hline
\end{tabular}

ED, emergency department; ICU, intensive care unit.

positive subjects. Of the 638 first positive cases, 624 were those found in phase 1 (up to 3 May 2020), which was $4.64 \%$ of the 13448 swabs performed during this period of time. Therefore, in the first 11 days of phase 2 (from 4 May to 15 May 2020), there were 14 newly positive subjects screened for SARS-CoV-2, which was $0.18 \%$ of the
7431 swabs performed (phase 1 vs phase 2 ; $\mathrm{p}<0.0001$, OR 25.827, $95 \%$ CI 15.195 to 43.614 ).

The main characteristics of the positive patients versus the negative patients are reported in table 1.

The distribution of patients found to be positive during phase 1 , on the basis of their symptoms, is reported in

Table 2 Prevalence of symptomatic and asymptomatic subjects stratified by result of nasopharyngeal swab

\begin{tabular}{|c|c|c|c|c|}
\hline & Overall, n (\%) & SARS-CoV-2-positive, n (\%) & SARS-CoV-2-negative, n (\%) & $P$ value \\
\hline Total & 13448 & 624 & 12824 & \\
\hline Total asymptomatic & $12275(91.3)$ & $470(75.3)$ & $11651(90.8)$ & $<0.0001$ \\
\hline Inpatients & $864(2.5)$ & $14(2.2)$ & $850(6.6)$ & \\
\hline ED patients & $342(2.5)$ & $21(3.4)$ & $321(2.5)$ & \\
\hline Occupational health surveillance & $1219(9.1)$ & $5(0.8)$ & $1214(9.4)$ & \\
\hline Total symptomatic & $1068(7.9)$ & $150(24.0)$ & $918(7.1)$ & $<0.0001$ \\
\hline Contacts (domiciliary isolation) & $756(5.6)$ & $126(20.2)$ & $630(4.9)$ & \\
\hline Inpatients & $152(1.1)$ & $9(1.4)$ & $143(1.1)$ & \\
\hline ED & $123(0.9)$ & $14(2.2)$ & $109(0.8)$ & \\
\hline Contacts (domiciliary isolation) & $81(0.6)$ & $2(0.3)$ & $79(0.6)$ & \\
\hline Inpatients & $1(0.01)$ & $1(0.2)$ & $134(1.0)$ & \\
\hline ED patients & $1(0.01)$ & $1(0.2)$ & $39(0.3)$ & \\
\hline ICU patients & 0 & 0 & $3(0.02)$ & \\
\hline Occupational health surveillance & 0 & 0 & $1(0.01)$ & \\
\hline
\end{tabular}

ED, emergency department; ICU, intensive care unit. 


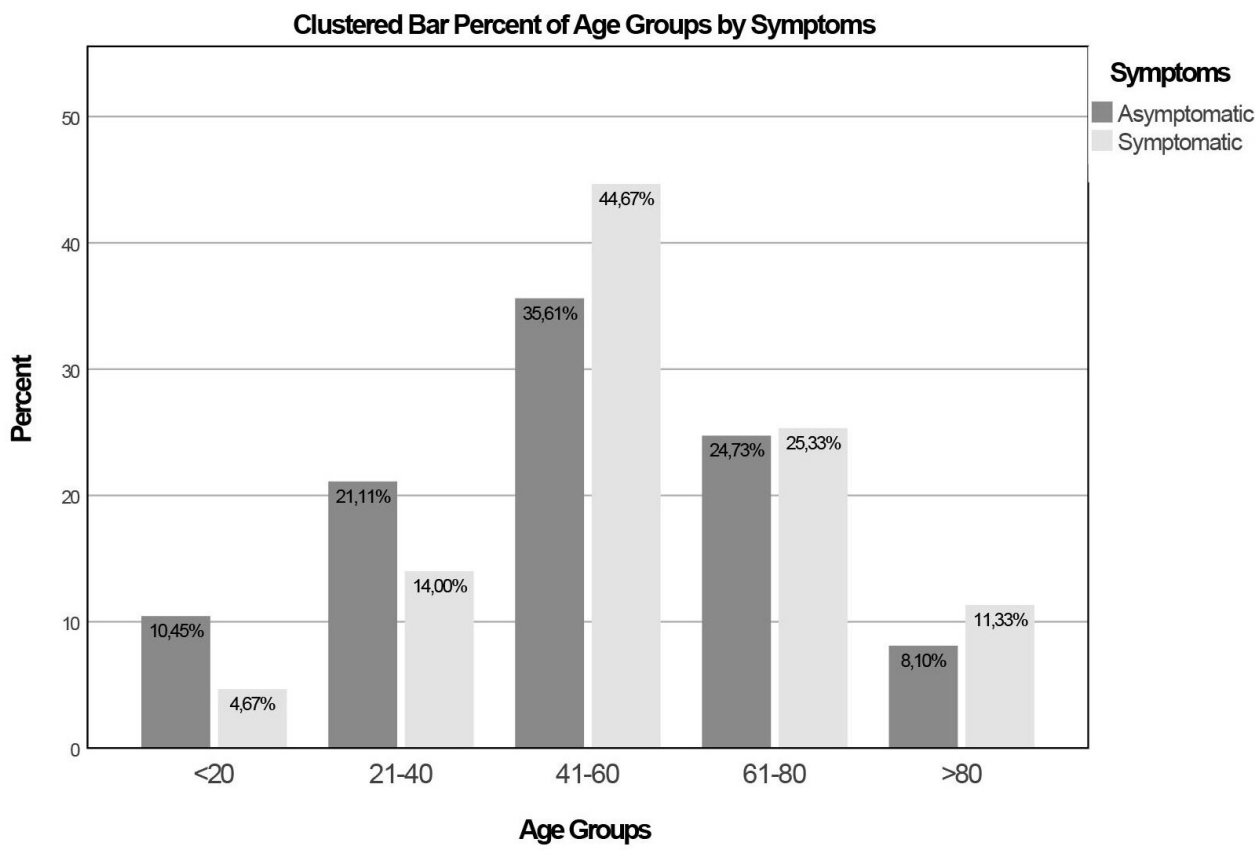

Figure 1 Prevalence of symptomatic and asymptomatic subjects among SARS-CoV-2-positive subjects, by age class.

table 2. From the two tables we can find that there were 556 so-called 'contacts' (persons on whom NS were primarily performed due to contact with a positive subject, such as family members, coworkers, caregivers, etc). Of these, $428(76.98 \%)$ were asymptomatic and 128 $(23.02 \%)$ had symptoms that were not enough to require hospitalisation and were therefore posed in domiciliary isolation. They represented $68.59 \%$ of the total positive patients screened in the province of Salerno.

As far as symptoms are concerned, all symptomatic SARS-CoV-2-positive subjects were more often of male gender with respect to asymptomatic ones; however, this finding did not reach statistical significance (male sex prevalence: $62.00 \%$ vs $53.94 \%$; $\mathrm{p}=0.084$, $\mathrm{OR}=1.393$, $95 \%$ CI 0.959 to 2.030 ). They were also significantly older (mean age $54.20 \pm 20.78$ vs $49.99 \pm 16.82$, $\mathrm{p}<0.0001$ ). Figure 1 shows the prevalence of symptomatic and asymptomatic carriers of SARS-CoV-2 by age class. There was a statistical difference in the $<20$ years and $21-40$ years age classes, where there were more asymptomatic positive subjects ( $\mathrm{p}=0.022$ and $\mathrm{p}=0.048$, respectively), and in the 41-60 years age class, where there were more symptomatic patients $(p=0.038)$. Finally, when analysing the prevalence of SARS-CoV-2 positivity among symptomatic and asymptomatic subjects, we found that the prevalence of positive NS among symptomatic patients was $14.04 \%$ (150 of 1068), whereas it was $3.82 \%$ (470 of 12 275) in asymptomatic subjects (relative risk ratio (RR): $3.668,95 \%$ CI 3.070 to $4.372, \mathrm{p}<0.0001)$.

The total number of NS specimens collected and processed 'per-day' is reported in figure $2 \mathrm{~A}$. The highest number of tests performed was on 4 May $2020 \quad(n=903)$. During phase 1 the mean number of tests performed was 263 per day; however, it was lower in the first weeks and higher in the last weeks due to efforts in improving the service. The percentage of positive NS 'per day' is reported in figure $2 \mathrm{~B}$. The highest number of positive NS was recorded on 26 March (57 of 363 tests performed, $15.7 \%)$. A constant decrease in the total number of positive subjects was then observed, reaching 0 during the last 4 days of phase 1 , despite the number of tests performed during these days being 1037. Moreover, as can be seen in figure $2 \mathrm{~B}$, the percentage of positive patients decreased constantly over time, in an inverse trend with respect to the increase in the total number of tests performed. Finally, figure 2C shows the daily percentage of symptomatic positive patients, showing a decreasing trend over time as well.

Of note, there were 918 patients $(6.83 \%$ of the total) who, even if repeatedly showing negative NS for SARS-CoV-2, presented themselves with symptoms that were compatible with any of the clinical presentations of COVID-19. These subjects were 'contacts' in the majority of cases $(68.6 \%)$, and the others were either admitted to the hospital ward $(15.6 \%)$, emergency department $(11.9 \%)$ or intensive care unit $(1.3 \%)$ (table 2).

Finally, we report the mean expression (displayed as 'cycle threshold' to obtain positive fluorescence in RT-PCR-C(t)) of the three genes of SARS-CoV-2 assays (N, $\mathrm{E}$ and RdRP) in subjects defined as positive. There was no statistically significant difference in the mean gene expression between asymptomatic and symptomatic subjects (table 3). However, when grouped in four age classes $(<25,26-50,51-75$ and $>75$ years of age), there was a statistically higher expression of RdRP and $\mathrm{N}$ genes in positive patients aged $>75$ years with respect to patients aged $<25$ years $(\mathrm{p}=0.036$ and $\mathrm{p}=0.032$, respectively) ( figure 3). 


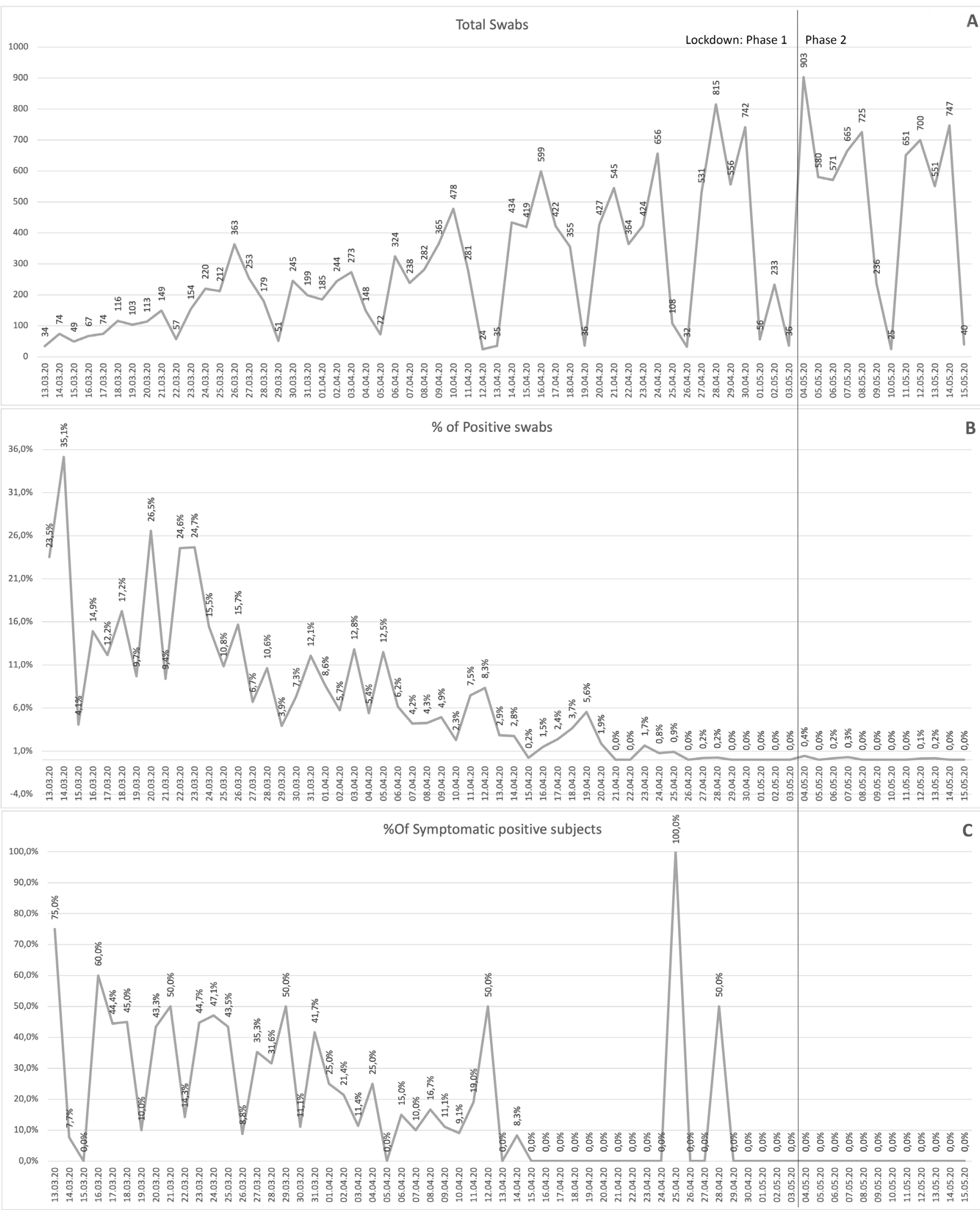

Figure 2 (A) Total number of executed SARS-CoV-2 swabs per day in the province of Salerno from 3 March to 15 May 2020. (B) Percentage of swabs that resulted positive among the total executed swabs per day. (C) Percentage of symptomatic patients among positive subjects per day. 
Table 3 Overall gene expression (presented as $\mathrm{C}(\mathrm{t})$ ) of the three genes of SARS-CoV-2 as detected by real-time PCR among positive patients and the differences between symptomatic and asymptomatic subjects, in mean $( \pm \mathrm{SD})$

\begin{tabular}{lllll}
\hline & Overall & Symptomatic & Asymptomatic & P value \\
\hline \multirow{2}{*}{ E gene C $(t)$} & 23.9040 & 22.2785 & 22.8605 & 0.486 \\
& $( \pm 4.28123)$ & $( \pm 4.97021)$ & $( \pm 4.88053)$ & \\
\multirow{2}{*}{ RdRP C $(t)$} & 25.1360 & 23.5495 & 24.1136 & 0.583 \\
& $( \pm 4.42040)$ & $( \pm 4.75518)$ & $( \pm 4.69109)$ & \\
\multirow{2}{*}{ N C $(t)$} & 26.4580 & 24.7405 & 25.4944 & 0.448 \\
& $( \pm 4.15840)$ & $( \pm 4.55574)$ & $( \pm 4.72231)$ & \\
\hline
\end{tabular}

$C(t)$, cycle threshold

\section{DISCUSSION}

Hereby we report on the experience of the healthcare system of a large area in Southern Italy in facing the coronavirus outbreak. As soon as COVID-19 became epidemic in Italy, several measures were set up to fight its spread. ${ }^{7}$ A profound and quick reorganisation of the healthcare system was done, restructuring clinical activities including increasing the capacity of intensive care units, establishment of the so-called 'COVID-hospitals', reallocation of healthcare professionals to face emergency cases and interruption of all non-urgent or unnecessary activities of the healthcare system. Even if the major outbreak was in Northern Italy, the central and southern regions of the country were also subjected to the same rules and precautions. ${ }^{14}$ A screening for COVID-19 infection was provided for those who were either symptomatic or at high risk of infection (see the Patients and methods section). Our university hospital was identified as one of the centralised centres dedicated to the execution of COVID-19-related biological tests. Moreover, during phase 1 of lockdown, all commercial and working activities that were considered not necessary (mostly alimentary, pharmaceutics and logistics) were shut down in Italy, with the warning to not leave home without valid reasons.
During phase 1 of lockdown, from a population of almost 1 million inhabitants in our province, we registered 624 total number of cases of SARS-CoV-2-positive subjects, which was $4.64 \%$ of 13448 NS performed. However, to correctly interpret these data, it has to be pointed out that a universal screening of the population was not provided in Italy at the time and it is still to be implemented. This was due to a series of factors including scarce availability of commercial tests worldwide and difficulties in organising a very large screening activity in a short period of time. Therefore, this fact raised several concerns in the scientific community and in the public opinion about the COVID-19 epidemiology, particularly regarding the possibility of transmission of the disease from asymptomatic subjects, as it has been reported since the very beginning of the outbreak. ${ }^{4-6}$ In fact, in the absence of a systematic screening of the entire population, several doubts can arise with regard to the safety of relaxing lockdown measures, due to lack of information on the prevalence of asymptomatic infection, as well as on its role in the spread of the pandemic. At the time of writing, there were no robust data on these points even if limited evidence seems to indicate that it is crucial to screen not the entire population but rather the high-risk populations and the close contacts of identified cases. ${ }^{6}$ In this way, our data can be a useful tool for stakeholders and medical authorities in Italy and Europe that are attempting to describe the epidemiology of the pandemic in order to find the best way to balance the recovery of normal social and commercial activities and the safety of the population. This is particularly crucial in the actual phase, when the vaccine programmes are being carried out by the healthcare authorities, in order to avoid both excessive relaxation of the safety rules (to give the time for carrying out the vaccination campaigns), or the application of excessive restrictions that, in turn, could further hit the socio-economic fabric of the affected nations. In fact, as mandated by Italian regulations, our screening was
A

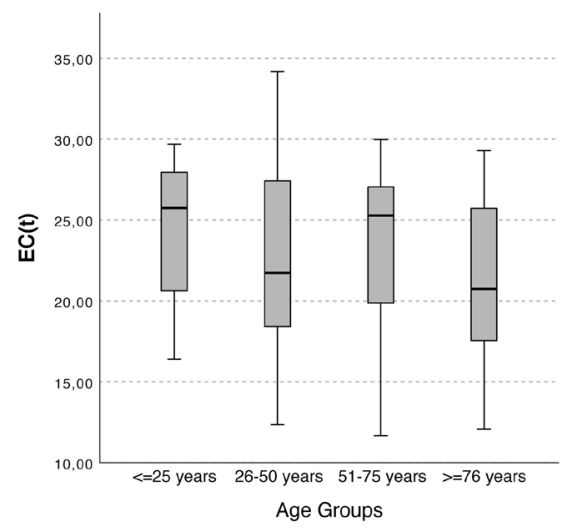

B

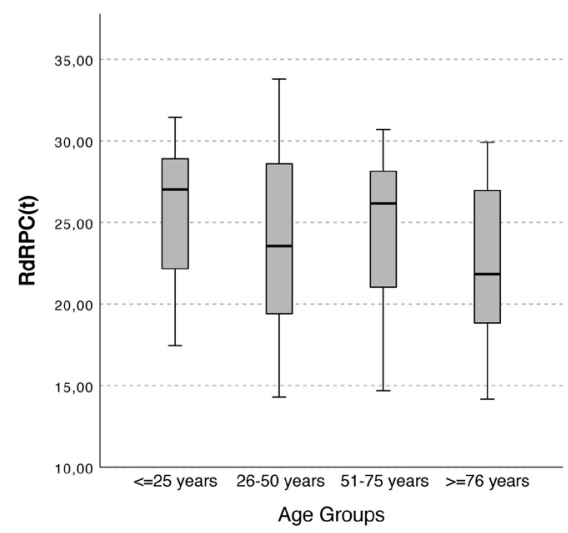

C

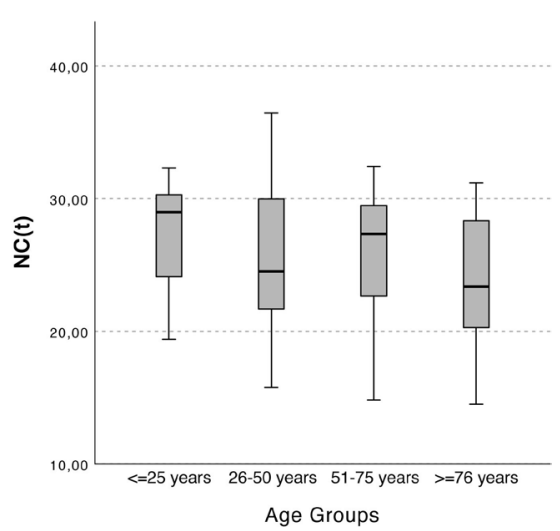

Figure 3 Expression (presented as $\mathrm{C}(\mathrm{t})$ ) of the three genes ((A) gene E; (B) gene rdRP; (C) gene N) of SARS-CoV-2 as detected by real-time PCR among positive patients stratified by four age classes $(<25,26-50,51-75,>76$ years). The only statistical differences were found in the mean expression of RdRP and N genes between the $<25$ and $>75$ years age classes, where significantly lower expressions (higher $\mathrm{C}(\mathrm{t}))$ were found in the older ones $(\mathrm{p}=0.036$ and $\mathrm{p}=0.032$, respectively, with a Bonferronicorrected Kruskal-Wallis pairwise comparison for independent samples). C(t), cycle threshold. 
performed exactly as suggested by the literature: apart from those who were admitted to emergency departments with a syndrome suggestive of COVID-19, all other NS were performed precisely on close contacts of positive cases (family member, cohabitants, coworkers, caregivers, etc) and on the highest risk population during phase 1 of lockdown, represented by healthcare workers for obvious reasons. As it can be deduced from the results of the present screening, majority of the SARS-CoV-2-positive subjects found during this phase were asymptomatic (470 of $624,75.3 \%$ ), and of these the vast majority were represented by close contacts of symptomatic cases ( 428 of 470 , 91.3\%), representing 3.2\% of the 13448 NS performed (see also tables 1 and 2). At first sight, this finding may be interpreted as an alarming point, but it should also be noted that the vast majority of positive cases were found precisely only among close contacts of symptomatic cases (556 of $624,89.1 \%$ ). Moreover, when analysing the prevalence of positivity among symptomatic and asymptomatic people, we found that it was significantly higher among symptomatic patients with respect to asymptomatic ones ( $14.04 \%$ vs $3.82 \%)$, with more than three times higher relative risk ratio of having the infection. This may in part be accounted for by the higher number of asymptomatic subjects screened (RR: $3.668,95 \%$ CI 3.070 to 4.372, $\mathrm{p}<0.0001)$. Another point of interest is that only $5(0.4 \%)$ subjects showed positive results among the 1239 healthcare workers screened weekly in the same period of time, demonstrating that, among such a high-risk population, the infection was marginal during this particular phase of the epidemic in the province of Salerno. This finding may be attributed to the correct use of personal protection equipment (PPE) among healthcare workers, confirming in particular the usefulness of face masks, as frequently reported. ${ }^{1617}$ However, the significant difference between the high prevalence of asymptomatic SARS-CoV-2-positive subjects between 'contacts' of infected cases with respect to the low prevalence among healthcare workers (and occasionally volunteers) suggests that the possibility of getting incidentally infected among the general population has to be rare if (and when) correct and rapid measures are applied in order to identify and appropriately follow up positive subjects and their contacts, along with containment measures.

The fact that the policy to primarily screen close contacts of positive subjects has been a successful approach may be demonstrated by the rapid decline in the number of positive subjects found over time, as depicted in figure 2 , where the total number of NS performed (figure 2A), the percentage of total positive ones (figure $2 \mathrm{~B}$ ) and the percentage of symptomatic positive ones (figure 2C) are reported. In fact, even if every day there was an increasing number of NS performed, there was also a constant decrease in the total number and in the percentage of symptomatic infected subjects, with only 14 cases out of 7341 NS found at the end of phase 1. This, in our opinion, demonstrates that 'social distancing' (in particular the lockdown of unnecessary activities and the mandatory use of face masks in the population) and the correct use of PPE by healthcare professionals, together with the systematic screening of close contacts, represented good measures to reduce the spread of infection in the province of Salerno during this phase.

Another critical point that stirred scientific debate during the early phase of the SARS-CoV-2 epidemic is the importance of viral load in defining the symptoms and infectiousness of the patients. ${ }^{18-21}$ In fact, there are conflicting data on this point, with some evidence pointing out that the high viral load of asymptomatic subjects may be accounted for in their infectiousness and therefore their dangerousness. ${ }^{21}{ }^{22}$ On the contrary other documents reported that asymptomatic infected subjects had lower viral loads, which may account for their lack of symptoms. ${ }^{23-28}$ On the other hand, the WHO pointed out, in a 'situation report' on the pandemic, that there are few evidence of asymptomatic transmission (COVID-19 Situation Report \#79) ${ }^{29}$ and that 'Available evidence from contact tracing reported by countries suggests that asymptomatically infected individuals are much less likely to transmit the virus than those who develop symptoms'. ${ }^{30}$ Our findings revealed that there were no statistically significant differences between symptomatic and asymptomatic SARS-CoV-2 virus carriers with regard to viral load (table 3). However, when analysed by age class, the SARS-CoV-2 gene expression showed a statistically significant difference in the RdRP and $\mathrm{N}$ genes, which were more expressed in older ( $>75$ years) than in younger $(<25$ years) patients, as shown in figure 3 , possibly suggesting that viral load may have had a marginal impact on the development of symptoms. In fact, asymptomatic subjects were also significantly younger and symptomatic subjects particularly represented the $41-60$ years age class (figure 1). Moreover, symptomatic subjects were more frequently of male gender. In this way, our data confirmed some of the characteristics of asymptomatic carriers reported by others, but also showed a certain correlation of age with symptoms and viral load. ${ }^{21-25} 27$ However, it is very likely that the lack of symptoms (no cough, no sneezing, no dyspnoea), along with 'normal' health condition and younger age, in subjects who therefore did not require any form of 'caregiving' (by families, cohabitants or healthcare personnel), which might have required 'close contact', together with correct social distancing measures, could be 'responsible' for the lower infectiousness of asymptomatic subjects rather than simply the lower viral load itself.

Finally, another interesting point arising from our data that needs to be discussed is the prevalence of hospitalised subjects who underwent NS due to symptoms suggestive of COVID-19 but were found negative. As per protocol, a patient who presents with symptoms strongly suggestive of COVID-19 but was found negative on the first NS was isolated in a 'grey zone', which was established with the purpose of accommodating unconfirmed cases, and then subjected to further confirmation tests in order to prevent the risk of false 
negatives. Nevertheless, in our cohort there were 918 subjects who had symptoms compatible with COVID-19 and with 'confirmed negative' results. They represented $6.82 \%$ of all NS and were mostly 'contacts' $(68.6 \%)$ or hospitalised patients $(28.75 \%)$. In particular, the last category is the most interesting: among those who were hospitalised and had symptoms suggestive of COVID19 , it is very likely that an infectious disease other than SARS-CoV-2 was in place. This finding has to be taken into account in the current phase, when vaccine campaign has started. In fact, it should be useful to consider 'taking the chance' to perform other vaccinations together with that for COVID-19, particularly for airborne infections (as influenza viruses).

There are some limitations to this study. First, as already mentioned, this was not a universal screening of the population and therefore we cannot affirm without any doubt that those who were screened were the only infected individuals in the geographical area tested. Nevertheless, it also has to be noted that the number of symptomatic patients drastically reduced over time, which is an indirect marker of the epidemic slowing down.

\section{CONCLUSIONS}

The combination of social distancing together with the systematic screening of close contacts of COVID19-positive symptomatic subjects seems to be an efficacious approach to contain the spread of the SARS-CoV-2 epidemic, suggesting then the rare eventuality of being occasionally infected by positive asymptomatic subjects.

Contributors MP is the guarantor of the manuscript. MM, $A B$ and MP conceived and designed the experimental study. MM, EV, RS, PT, AA, ADV, RC and AB performed the epidemiological evaluations and data collection. MM and PT performed the statistical analysis. MP and MM wrote the manuscript. MP and AB edited the manuscript. All authors approved the final version of the manuscript.

Funding The authors have not declared a specific grant for this research from any funding agency in the public, commercial or not-for-profit sectors.

Competing interests None declared.

Patient consent for publication Not required.

Ethics approval The present study was approved by our local ethics committee (Ethics Committee of Campania Sud (cometicocampaniasud@asInapoli3sud.it; protocol number 102 of 3 July 2020) and conducted in conformity with the ethical guidelines of the 1975 Declaration of Helsinki.

Provenance and peer review Not commissioned; externally peer reviewed.

Data availability statement Data will be available upon request to the corresponding author (MP).

Open access This is an open access article distributed in accordance with the Creative Commons Attribution Non Commercial (CC BY-NC 4.0) license, which permits others to distribute, remix, adapt, build upon this work non-commercially, and license their derivative works on different terms, provided the original work is properly cited, appropriate credit is given, any changes made indicated, and the use is non-commercial. See: http://creativecommons.org/licenses/by-nc/4.0/.

ORCID iDs

Mario Masarone http://orcid.org/0000-0003-0550-8201

Marcello Persico http://orcid.org/0000-0002-1399-6498
REFERENCES

1 World Helath Organization. WHO Timeline - COVID-19, 2020. Available: https://www.who.int/news-room/detail/27-04-2020-whotimeline-covid-19 [Accessed 13 Jun 2020].

2 GIMBE. Coronavirus Pandemic - Monitoring page of the COVID-19 epidemic in Italy, 2020. Available: https://coronavirus.gimbe.org/ coronavirus-emergency-italy.en-GB.html [Accessed 13 Jun 2020].

3 Huang C, Wang Y, Li X, et al. Clinical features of patients infected with 2019 novel coronavirus in Wuhan, China. Lancet 2020;395:497-506.

4 Bai Y, Yao L, Wei T, et al. Presumed asymptomatic carrier transmission of COVID-19. JAMA 2020;323:1406.

$5 \mathrm{Hu}$ Z, Song C, Xu C, et al. Clinical characteristics of 24 asymptomatic infections with COVID-19 screened among close contacts in Nanjing, China. Sci China Life Sci 2020;63:706-11

6 Gao Z, Xu Y, Sun C. A systematic review of asymptomatic infections with COVID-19. J Microbiol Immunol Infect 2020.

7 Region C. Coronavirus Outbreak - Campania Region ordinances and measures, 2020. Available: http://www.regione.campania.it/regione/ it/la-tua-campania/coronavirus-kyxz [Accessed 13 Jun 2020].

8 Salerno A. ASL Salerno healthcare structures, 2020. Available: http:// www.aslsalerno.it/web/guest/chi-siamo [Accessed 13 Jun 2020].

9 World Helath Organization. Laboratory testing for coronavirus disease 2019 (COVID-19) in suspected human cases: interim guidance, 2020. Available: https://apps.who.int/iris/bitstream/ handle/10665/331329/WHO-COVID-19-laboratory-2020.4-eng.pdf [Accessed 13 Jun 2020].

10 Marty FM, Chen K, Verrill KA. How to obtain a nasopharyngeal swab specimen. N Engl J Med 2020;382:e76.

11 World Helath Organization. Novel coronavirus (2019-nCoV) technical guidance 2020, 2020. Available: ttps://www.who.int/emergencies/ diseases/novel-coronavirus-2019/technical-guidance [Accessed 13 Jun 2020].

12 CDC - Centers for Diseases Control and Prevention. Interim guidelines for collecting, handling, and testing clinical specimens for COVID-19 web, 2020. Available: https://www.cdc.gov/coronavirus/ 2019-nCoV/lab/guidelines-clinical-specimens.html [Accessed 13 Jun 2020].

13 Farfour E, Lesprit P, Visseaux B, et al. The Allplex 2019-nCoV (Seegene) assay: which performances are for SARS-CoV-2 infection diagnosis? Eur J Clin Microbiol Infect Dis 2020;39:1997-2000.

14 Fagiuoli S, Lorini FL, Remuzzi G, et al. Adaptations and lessons in the province of Bergamo. N Engl J Med 2020;382:e71.

15 Grasselli G, Pesenti A, Cecconi M. Critical care utilization for the COVID-19 outbreak in Lombardy, Italy: early experience and forecast during an emergency response. JAMA 2020;323:1545-6.

16 Zhang R, Li Y, Zhang AL. Identifying airborne transmission as the dominant route for the spread of COVID-19. Proc Natl Acad Sci U S A 2020.

17 Cheng VC, Wong SC, Chan VW. Air and environmental sampling for SARS-CoV-2 around hospitalized patients with coronavirus disease 2019 (COVID-19). Infect Control Hosp Epidemiol 2020:1-32.

18 Zheng S, Fan J, Yu F, et al. Viral load dynamics and disease severity in patients infected with SARS-CoV-2 in Zhejiang Province, China, January-March 2020: retrospective cohort study. BMJ 2020;369:m1443.

19 Azkur AK, Akdis M, Azkur D, et al. Immune response to SARS-CoV-2 and mechanisms of immunopathological changes in COVID-19. Allergy 2020;75:1564-81.

20 Yoon JG, Yoon J, Song JY, et al. Clinical significance of a high SARSCoV-2 viral load in the saliva. J Korean Med Sci 2020;35:e195.

21 Arons MM, Hatfield KM, Reddy SC, et al. Presymptomatic SARSCoV-2 infections and transmission in a skilled nursing facility. $N$ Engl J Med 2020;382:2081-90.

22 Han MS, Seong M-W, Kim N, et al. Viral RNA load in mildly symptomatic and asymptomatic children with COVID-19, Seoul, South Korea. Emerg Infect Dis 2020;26:2497-9.

23 Furukawa NW, Brooks JT, Sobel J. Evidence supporting transmission of severe acute respiratory syndrome coronavirus 2 while presymptomatic or asymptomatic. Emerg Infect Dis 2020;26.

24 Hoehl S, Rabenau H, Berger A, et al. Evidence of SARS-CoV-2 infection in returning travelers from Wuhan, China. $N$ Engl J Med 2020;382:1278-80.

25 Kam K-Q, Yung CF, Cui L, et al. A well infant with coronavirus disease 2019 with high viral load. Clin Infect Dis 2020;71:847-9.

26 Le TQM, Takemura T, Moi ML, et al. Severe acute respiratory syndrome coronavirus 2 shedding by travelers, Vietnam, 2020. Emerg Infect Dis 2020;26:1624-6.

27 Zou L, Ruan F, Huang M, et al. SARS-CoV-2 viral load in upper respiratory specimens of infected patients. $N$ Engl J Med 2020;382:1177-9. 
28 Kimball A, Hatfield KM, Arons M, et al. Asymptomatic and

Presymptomatic SARS-CoV-2 Infections in Residents of a Long-Term Care Skilled Nursing Facility - King County, Washington, March 2020 MMWR Morb Mortal Wkly Rep 2020;69:377-81.

29 World Health Organization. Coronavirus disease 2019 (COVID-19) situation report -73 online, 2020. Available: https://www.who.int/ docs/default-source/coronaviruse/situation-reports/20200402-sitrep73-covid-19.pdf?sfvrsn=5ae25bc7_2\# [Accessed 13 Jun 2020].

30 World Health Organization. Transmission of COVID-19 by asymptomatic cases online, 2020. Available: http://www.emro. who.int/health-topics/corona-virus/transmission-of-covid-19-byasymptomatic-cases.html [Accessed 16 Jun 2020]. 